\title{
Contribuciones actuales de la Geografía de género y homosexualidad desde el espacio urbano
}

\author{
Current contributions of Geography of \\ gender and homosexuality from \\ the urban space
}

\author{
Jazmin Paz* \\ Lucinda Arroyo** \\ Oscar Frausto**
}

Fecha de recibido: 06 de enero de 2019

Fecha de aceptado: 01 de octubre de 2019

\section{Resumen}

En este artículo se expone una revisión analítica actual de las vitales contribuciones, en especial latinoamericanas y de otros países, en la construcción teórica-investigativa del espacio urbano, con perspectiva de género, específicamente homosexual. Con la finalidad de evidenciar cómo la comunidad gay y hombres habitan interconectadamente espacios y donde producen significados de formas diversas dentro de la ciudad. Y de esta manera contribuir en la comprensión de las formas adyacentes en la conformación de espacios para las prácticas emancipatorias en lo urbano y social, ya que las dinámicas homosexuales y el espacio público, son uno de los componentes sustanciales de la ciudad. Para tal objetivo se llevó a cabo la exploración de libros, artículos científicos e investigaciones a partir de la década de los noventa hasta la actualidad. Donde se logró identificar concepciones teóricas, ejes temáticos, así como problemáticas particulares encontradas en los distintos ámbitos de la

Universidad de Quintana Roo, Campus Chetumal, México, correo electrónico: jazpaz1306@gmail.com

** División de Desarrollo Sustentable y Departamento de Estudios Sociales y Empresariales, Universidad de Quintana Roo, Campus Cozumel, México, correos electrónicos: luarroyo0510@gmail.com; fraustomartinezoscar@gmail.com 
investigación. De igual manera, se expresan desafíos pendientes en cuanto al desarrollo de las manifestaciones espaciales de la homosexualidad.

Palabras claves: Geografía de género, homosexualidad masculina, comunidad gay, espacio urbano y ciudad.

\begin{abstract}
This article presents a current analytical review of the vital contributions, especially from Latin America and other countries, in the theoretical-research construction of the urban space, with a gender perspective, specifically homosexual. In order to show how the gay community and men live interconnected spaces that occupy and where they produce meanings of different forms within the city. And in this way contribute in the understanding of the adjacent forms in the creation of spaces for emancipatory practices in the urban and social, since the homosexual dynamics and the public space, are one of the substantial components of the city. For this purpose, the exploration of books, scientific articles and research was carried out from the decade of the nineties until now. Where it was possible to identify theoretical conceptions, thematic axes, as well as particular problems found in the different fields of research. In the same way, pending challenges are expressed regarding the development of the spatial manifestations of homosexuality currently.

Palabras clave: gender Geography, male homosexuality, gay community, urban space and city.
\end{abstract}

\title{
Introducción
}

Este estudio examina cómo el tema de género y espacio -principalmente en Latinoamérica- se ha instaurado en la academia a través de los estudios urbanos, logrando una contribución reflexiva y un deber hacia distintos aportes, que generen de esta manera un nuevo horizonte de conocimiento actual en la geografía humana. Así, se hace evidente el fortalecimiento de estos estudios, mediante su variabilidad, lo que ha favorecido -aunque de manera menos proporcional al de otras áreas de estudio-, en el establecimiento de otras maneras de entender y explicar la relación entre la homosexualidad masculina y la geografía desde una visión más amplia, esencialmente en la producción del espacio público y social. Desde esta óptica, tendremos el caso de homosexualidad masculina, denominada desde el adjetivo "gay" (Seva, 2011).

Asimismo, en este trabajo fueron analizados los desafíos que aún quedando pendientes, y que pueden ayudar a contribuir hacia una geografía homosexual del espacio público. De esta manera, enfocarnos en la dimensión espacial de la realidad social de América Latina, nos ayudará a tener claridad acerca de la 
producción académica generada en cuanto al estudio de la ciudad, basado en la categoría de género y desde la dimensión geográfica, donde se exponen diferencias sociales y contrastes territoriales en el espacio urbano, que distingue a la comunidad gay de los demás grupos sociales, logrando de esta manera, fomentar la transversalidad y diversificación de estudios en la esfera académica. Por consiguiente, se presenta el repertorio de contribuciones desde la geografía de acuerdo a ejes temáticos.

Dado que aún permea la capacidad de estudio de este tema, - debido a que no se ha logrado equiparar la espacialidad de los hombres gais desde un enfoque local, y a pesar de que las investigaciones actuales empíricas acerca del fenómeno social de la homosexualidad y la producción del espacio urbano han mostrado avances paulatinos, pero significativos - la realidad es que estos hallazgos aún siguen permaneciendo desincorporados en un marco teórico sólido que los articule y sobre todo que los explique.

Por consiguiente, es necesario exponer que este estudio es parcialmente un referente de acercamiento, que busca concebir una extensión generalizada, que manifieste los aportes, avances y formas en las que se está generando conocimiento según las tendencias ofertadas a través de los escritos aquí analizados, en las cuales se han producido elementos analíticos acerca de la comunidad gay y la ciudad. Ello ha contribuido a espacios de diálogo y reflexión, aunque con varias limitantes.

Aunado a esto, también se pudo constatar que los escritos han sido publicados básicamente en revistas de corte connacional -con algún alcance regional-. Esto logra explicarse a través de dos aspectos: por un lado, porque a pesar de las interesantes aportaciones que la Geografía ha prestado a las minorías sexuales todavía existe cierta marginalidad científica (Dóniz, 2015) y por otro, porque se requieren de nuevas metodologías que se acerquen a estos espacios-otros que están presentes en lo cotidiano del paisaje urbano. De ahí la pertinencia de críticas feministas y de lecturas transgresoras que ayuden a rehacer la disciplina geográfica, sus teorías y su forma de estar en el campo. "Joder a la geografía" implica cuestionar las políticas académicas de lo que es apropiado para investigar y de lo que es (i)legítimo como conocimiento para observar los múltiples y variados matices de nuestros entornos espaciales (Ramírez, 2013).

La fase analítica fue organizada bajo tres categorías. La primera está enfocada en especificar la relación entre el espacio público y la homosexualidad masculina, exponiendo también el papel del urbanismo en la producción de la identidad gay. En la segunda se exploran las tres subdisciplinas que han contribuido en el análisis geográfico del género homosexual: Geografía de género y feminismo, de las sexualidades y de la diversidad. Finalmente, en la tercera se establece de manera breve y generalizada las tres dimensiones en las que ha sido estudiada la homosexualidad masculina y el espacio: turismo gay, turismo sexual y prostitución gay, y marketing gay, porque el análisis está centrado en puntualizar 
los trabajos latinoamericanos que han abordado la concepción de lugares de socialización o interés gay, así como el estudio de su visibilidad.

\section{Relación de los estudios urbanos con la identidad gay}

El cruce entre ciudad y género, como perspectiva de análisis, hace visible un conjunto de inequidades y desigualdades en el acceso a las oportunidades de vida en la ciudad. Estas conexiones presentan nuevos "puntos de entrada" para abordar los complejos desafíos que caracterizan los fenómenos urbanos en la actualidad. Al mismo tiempo, permiten incorporar la categoría de género como una variable crucial en el desarrollo (Saborio, 1999).

De lo contrario, advierten Román y Velázquez (2008), si se viese el espacio a la medida de un modelo único, no solo entorpece la vida de quienes no responden a esas características originales, sino que conllevan a no visibilizar y no reconocer otras formas de vida y necesidades. Con lo que éstas terminan por hacerse imposibles en un espacio que no las ha tenido en cuenta, por lo que tienden a ocultarse o a desaparecer. Así se crea un círculo vicioso asociado a una forma hegemónica de utilizar, comportarse y vivir la ciudad. Esto significa abarcar la diversidad mediante un urbanismo con perspectiva de género.

Por lo tanto, geógrafos, teóricos del género y queer, y académicos urbanistas necesitan reconocer más ampliamente que la identidad $-\mathrm{y}$ la identidad gay en particular - se construye socialmente (Ruiz, 2012). Tal y como lo plantean Barrios y Hernández (2015) la geografía de género y la geografía urbana deben preocuparse por reconocer dentro de una misma sociedad, los diversos agentes que influyen en ésta, influenciando directamente sus relaciones sociales, políticas económicas y de poder, a pesar de que todavía en la actualidad los estudios sobre la geografía urbana y el género estén prejuiciados e infravalorados dentro de los ámbitos académicos. Por lo que, probablemente esta limitación se debe, según Saborio (1999) a que existe una fuerte tendencia a considerar "lo urbano" como aquello referido a los espacios sociogeográficos habitados por una población homogénea, a lo más, dividida en clases sociales. Se trabaja así con las categorías cerradas o supuestamente neutras, que no dan cuenta de la diversidad ni de las inequidades.

Antes de seguir en el desarrollo del tema es indispensable conocer la diferenciación entre los conceptos de urbanismo y geografía urbana. Entiéndase al primero como la disciplina o práctica social, de carácter eminentemente técnico y voluntario, destinada a la reforma de la situación actual y a la ordenación del desarrollo espacial y temporal futuro de una ciudad, de acuerdo con las necesidades materiales y sociales de los habitantes de dicha ciudad; las actuaciones destinadas a tal fin se concretan en el plan, instrumento por excelencia de la intervención y gestión urbanística (Sánchez, 1992). Por su parte, la geografía urbana es la rama o disciplina geográfica que estudia la ciudad desde el punto de vista espacial, con una doble óptica: como entidad espacial autónoma 
y como parte integrante de una red urbana o sistema territorial de ciudades (Sánchez, 1992). Entendida esta diferenciación conceptual, se da paso al desarrollo de este tema.

Históricamente, no fue hasta la década de los setenta, que las redes sociales y la agitación cultural finalmente estalló en la consolidación visible de la vida sexual gay urbana con objetivos sociales, económicos y políticos más amplios. Las ciudades eran la plataforma perfecta para las comunidades gais emergentes, precisamente porque estaban fortificadas por las fuerzas de la oposición política y social (Ruiz, 2012).

Fue entonces que, en prácticamente todos los contextos, la identidad gay alcanzó auge y protagonismo; creó distintas posibilidades de expresión, así como espacios para ser enunciada en ellos (Balbuena et al., 2013), por lo que los hombres homosexuales se involucraron principalmente en el desarrollo de las comunidades gay urbanas (Ruiz, 2012). Incluso podríamos afirmar que esta identidad fomentó la organización, la enunciación y la manifestación pública de la homosexualidad (Balbuena et al., 2013). Y de esta forma, los impulsores sociales, económicos y políticos del urbanismo construyeron socialmente nuestra noción contemporánea de una "identidad gay" (Ruiz, 2012).

En algunas ciudades del mundo occidental, a principios de los años setenta del siglo pasado, se dio una circunstancia sociourbana hasta entonces singular: la aparición de zonas urbanas, cuyos espacios públicos y privados se iban ocupando y orientando, específicamente, por un segmento de la población que compartía, no una religión ni un origen étnico, ni tampoco una actividad laboral, sino su identificación para compartir una orientación sexual diferente a la de la mayoría heterosexual, hasta entonces la única aceptada socialmente (San Martín, 2010). De tal modo, la constitución de un espacio público restringido no impidió, sin embargo, que los "no reconocidos" y los "invisibilizados" desarrollasen formas propias de sociabilidad y de cultura en los márgenes o de manera paralela a la de los ciudadanos (Kingman, 2009).

Lo cual, dentro del crecimiento de las ciudades, algo descontrolado y explosivo que se ha evidenciado a través de la historia desde finales del siglo xIx y principios del $\mathrm{Xx}$, se puede afirmar que lo que consolidó este auge en las ciudades era la diversidad de individuos que llegaron a apoyar voluntaria o involuntariamente el crecimiento de las ciudades. Grupos de personas que organizaban guetos donde vivir, asociándose ya sea por compartir ideales políticos, costumbres de vida o algún otro motivo que los uniera para poder convivir de una forma más agradable y pasiva. Es de esta misma forma como se afianzó y se dió inicio a la formación y consolidación de asentamientos y/o distritos homosexuales o gais en diferentes ciudades del mundo, lo cual no es algo nuevo (Barrios y Hernández, 2015).

En México, a partir de la década de los setenta del siglo pasado, el movimiento homosexual alcanzó visibilidad en el espacio público al manifestar sus demandas y mostrando el abuso sistemático del que eran víctimas (Balbuena et al., 2013), 
donde según Lozano (2016) la manifestación pública de un grupo de personas que se autodenominaron "homosexuales" generó efectos mediáticos y sociales importantes.

Así, a partir de la era de la revolución sexual, la identidad gay comenzó a conformarse como un modelo de actuación política y también como estilo de vida que predominó en distintas partes del mundo, normalizando la disidencia que caracterizaba a los homosexuales (Balbuena et al., 2013). Combinados, estos factores convirtieron las concentraciones espaciales gay en comunidades reales con identidades (Ruiz, 2012). Sin embargo, que la sociedad llegara a tolerar esta presencia espacial, supuso un proceso largo y no exento de conflictos (San Martín, 2010).

Al discutir la relación entre la organización política gay y el espacio público a principios de los años setenta, Balbuena et al. (2013) señalan que la instauración de espacios diferenciados, ofrecen condiciones esenciales para que en los espacios públicos la homosexualidad comience a ser enunciada y hasta discutida. Por consiguiente, el movimiento espacial de gais en espacios urbanos facilitó la construcción social de comunidades (Ruiz, 2012) lo que generó configuraciones sociales inversamente proporcionales a las ortodoxas.

Por otro lado, dentro del análisis urbano en las relaciones de género San Martín (2010) propone dos modelos socioespaciales para explicar la dimensión pública del predominio de la comunidad gay; el modelo territorial integracionista y el comunitarista. El primero funciona en la medida que no perturba demasiado la homogeneidad urbana heterosexual (San Martín, 2010), esto significa que en el ámbito urbano en el que se expresa la homosexualidad masculina, la sociedad que la habita es respetuosa, tolerante e inclusiva por lo que el gay no tendrá la necesidad de resguardarse en espacios exclusivos y podrá integrarse de manera natural al contexto en el que se encuentra.

Por otra parte, el modelo territorial comunitarista ha funcionado en muchas ciudades como espacio de resistencia y de libertad para la comunidad gaylésbica, y a menudo no han sido radicalmente exclusivistas porque también la población heterosexual los ha frecuentado como lugar de diversión. Sin embargo, sus riesgos son el potencial aislamiento del resto de la sociedad, la banalización de la vida gay, e incluso una amenaza a la aparente homogeneidad social que puede desembocar en un incremento de la homofobia (San Martín, 2010).

Así y desde esta propuesta, se presentan dos posibilidades de conducir una sexualidad y una identidad desde lo urbano, que permita la representación de la dimensión espacial gay conjugada en los territorios normados y anclada en significados discontinuos de los propios modelos ofrecidos, que además pueden ser opcionales a una interrelación.

Por otro lado, y de acuerdo a la concepción perceptiva del espacio urbano, Gutiérrez y Guadarrama (2018) afirman que la urbe revela lo que se quiere ver, pero esconde lo que se quiere observar, de tal forma la ciudad necesita de una profundidad que admire su superficie, y de una redirección de la gloria de sus 
banalidades y sus prejuicios. Ello significa que los espacios urbanizados no tienen una delimitación tangible, sino invisibilidades espaciales que viven sólo dentro de la misma ciudad y la individualidad de los habitantes, los cuales reconfiguran sus sitios de acuerdo a los roles jugados por las circunstancias que desnudan las percepciones de las dificultades de los lugares en la ciudad. De esta manera se puede constatar que, a falta de concreciones, se tocan confusiones que ritualizan la vida cotidiana de la urbanidad (Gutiérrez y Guadarrama, 2018).

Se trata pues de ese espacio simbólico pero perceptible lleno de connotaciones y significados variados, que conjugan formas y modelos de coexistir en lo urbano y lo social; son formas sensibles que tienen una locución propia que desarticula y desafía las manifestaciones espaciales heterodoxas, revolucionando las apropiaciones desde contextos ideológicos heterogéneos. En concreto, en relación al ámbito del urbanismo y la homosexualidad, autores como Ruiz (2012) y Gutiérrez y Guadarrama (2018) hicieron énfasis en la relación de este proceso de producción del espacio urbano en la que se generaron elementos de trasformación y uso del espacio público, basados en las nuevas formas de representar la identidad desde un entorno social y espacial, basado en un modelo fuera de la heteronormatividad.

De tal manera, tanto la exposición de los procesos sociales como los cambios urbanos, explican cómo se establecen las dinámicas socioespaciales en los procesos de identidad, que transforman los modos de habitar los espacios, de significar en el entorno y de mantenerse inherente a las demandas que componen esa identidad gay en el espacio público. Esta lucha por conseguir igualdad en y desde la ciudad se vislumbra de manera paulatina, ya que en lo urbano está ese espacio de decisión, actuación, visibilidad, producción e identidad. De tal modo, el espacio público -como el espacio territorial o simbólico- al que se liga la homosexualidad, es fruto del debate ciudadano, aunque se encuentre plagado de acusaciones con pocos recursos reflexivos (Balbuena et al., 2013).

Defender un urbanismo gay es favorecer un espacio público inclusivo en el que la homosexualidad masculina se vea resignificada y legitimada, procurando manifestarse de manera proporcional a la heterosexualidad, disminuyendo la carga abyecta de este colectivo, a fin de interrelacionar ambas categorías de género en un mismo espacio, respectando cualidades diferentes, pero a su vez ayudando a evitar resaltar desigualdades, es decir, intervenir y cohabitar en la ciudad.

La introducción de la dimensión de género en la reflexión y acción sobre la ciudad permite reconocer que el espacio no es neutro y que los roles y actividades de hombres y mujeres en sus territorios y recorridos condicionan la percepción, acceso y uso de la ciudad, así como su vida cotidiana y sus experiencias, las que pueden ser cualitativamente diferentes entre sí (Quintero y Fonseca, 2008). Desde esta perspectiva es posible conocer, interpretar y discutir las vinculaciones existentes entre las relaciones de género socialmente construidas y el espacio urbano socialmente producido (Saborio, 1999). 
Según Apodaka (2012), con ello conseguiremos incrementar el sentimiento de pertenencia de cada ciudadana y ciudadano a su entorno urbano, así como su identificación y corresponsabilidad con la gestión cotidiana de su ciudad, porque según Balbuena et al. (2013) en el espacio público, la homosexualidad ha ceñido un sendero que con bastantes certezas le asegura el alcance total de una ciudadanía que responda a las exigencias de estos tiempos.

Aunque en contraste, Lozano (2016) exponga que en la actualidad el fin del proyecto gay en México ha sido la mímesis, la reproducción y la repetición del sistema heteronormal. En esta mímesis, el movimiento gay hace una especie de pacto con el Estado, se articula con él y desde ese poder se define de qué manera puede ingresar la diversidad sexual a la realidad sociopolítica.

Si bien es cierto que los gais a través de la apropiación urbana se han visibilizado, así como sus espacios, no en todos los contextos se pueden ver plasmadas estas trasformaciones también físicas de dichos sitios, esto, muy probablemente, por un lado, debido a la prevalencia de una sociedad ortodoxa y prejuiciosa hasta en nuestros días, y, por el otro, porque muchos hombres, a pesar de identificarse como gay u homosexual, no se sienten parte de la comunidad o de la vida política gay. Muestran un discurso politizado, pero ellos no se viven como parte de la vida política, ni se incluyen en las demandas hechas por el movimiento gay actual (Lozano, 2016).

La situación actual en la que se identifican distintos grupos sociales exigen un cambio radical en las formas de representarse en la ciudad y de apropiarse en el territorio urbano. Es un tema que debe no solo ser asumido desde la ciencia geográfica, sino a través de todas instituciones, organizaciones y sociedad en general. Al avanzar hacia este horizonte, se logrará que esa comunidad negada por el urbanismo convencional incorpore a sus criterios de ciudad, aquellos discursos de género considerados socialmente intangibles, porque según (Velázquez, 2012) en la creación de un urbanismo adecuado para la nueva sociedad es importante definir quiénes son los actores de estos nuevos espacios urbanos y qué papel juegan.

Finalmente, y en este marco emergente de nuevas identidades, los gais se proyectan en espacios de conflictos urbanos debido a que activan su recurso identitario estableciendo nuevas prácticas encaminadas a la transferencia de la democratización del espacio público. Porque en la realidad, las relaciones entre ciudad y género dan cuenta de un conjunto de inequidades y desigualdades sociales que se expresan en el espacio. Y estas conexiones presentan también potencialidades para generar cambios hacia condiciones de mayor igualdad (Saborio, 1999).

\section{La homosexualidad masculina desde el análisis geográfico}

Para el geógrafo Ramírez (2013) el estudio de lo impropio debe ser parte de la disciplina geográfica, ya que le permite expandir horizontes y desafiar territorios 
epistemológicos dados por hecho, para dar cuenta de lógicas espaciales que, de otro modo, pasan desapercibidos por lecturas racistas, patriarcales, heteronormativas y homonormativas de los espacios.

Significa que la homosexualidad no debe alejarse del pensamiento geográfico, porque así puede interpretarse de un modo sustancial e interdisciplinario su apropiación urbana, siendo una herramienta de comprensión en el análisis de la construcción del espacio público y la visibilización de identidades locales, ayudando a generar explicaciones certeras acerca del desarrollo y la transformación urbana, así como procesos asociados al urbanismo en sus distintas dimensiones.

Es por ello que este apartado pretende explorar las tres subdisciplinas que han contribuido en el análisis geográfico del género homosexual: deografía de o del género y feminismo, de las sexualidades y de la diversidad. En cuanto a la serie de estudios procedentes desde la disciplina geográfica, existen matices y paradigmas diferentes que versan sobre tres ejes principalmente, y de las que hemos clasificado para dar un sentido más lógico a la exposición del tema y que tienen incidencia directa a dicho estudio de la homosexualidad con el espacio y además cabe mencionar que son de carácter no exhaustivo.

\section{La Geografía de o del género y el feminismo}

Partiendo del supuesto de que el género es una perspectiva activa dentro de la geografía, que participa de las discusiones teóricas, epistemológicas y metodológicas de nuestra ciencia, colaborando en la construcción de su desarrollo (Veleda y Lan, 2007) se establece el análisis de la interrelación entre estos dos pensamientos.

El género en la geografía ha sido abordado por autores como: Soto, 2018; Lan, 2016; Veleda, 2016; Hancok y Chapuis, 2016; Dóniz, 2015; Fimiani, 2014; Trachana, 2013; Cattan y Leroy, 2010; Páramo y Burbano, 2011; Boivin, 2011; Quinceno y Sanín, 2009; Fonseca y Quintero, 2008; García, 2008; Fernández, 2007; Leroy, 2005; McDowell, 2000; García, 2000; Saborio, 1999; Ayllón, 1997; Pacheco, 1997; Massey, 1994 y Karsten y Meertens, 1991; por mencionar algunos. En general, los estudios vinculados hacia el género homosexual y la geografía en Latinoamérica son los de Gutiérrez y Guadarrama, 2018; Olarte, 2017; Espinosa, 2017; Aguilar, 2015; Robles, 2015; Bobadilla, 2013; Balbuena et al., 2013; Cancino, 2012; Moral, 2011; Laguarda, 2010; San Martín, 2010; Sánchez, 2004. De tal manera se puede aseverar que en el estudio de la geografía de género intervienen al menos cuatro elementos de análisis: género, espacio, identidad y urbanismo.

Para empezar, y desde la afirmación de Baylina (2016), el concepto de género es el instrumento teórico y político que el feminismo adopta a partir de los años 60 y principios de los 70 para hacer visible que las desigualdades y la opresión de las mujeres no tienen un origen biológico sino que son un producto social. 
Se puede ver que el análisis de la participación de la mujer en la geografía académica y profesional ha acaparado una buena parte de los estudios feministas en Estados Unidos, Gran Bretaña, Canadá y recientemente en España (García, 1985). Es en el ámbito anglosajón el primero que recoge estas demandas y las transforman en análisis para dar solución a los problemas que surgen en relación a las desiguales relaciones entre el género y el espacio (Baylina, 2016). No obstante, en América Latina, Brasil, Argentina, México, Colombia, entre otros, también han sido tocados por estos fenómenos (Veleda y Lan, 2007).

Parafraseando a Veleda y Lan (2007) en Latinoamérica la geografía del género forjó su desarrollo en Brasil y Argentina tras los movimientos feministas generados en la década de los setenta. Es por ello que, al intentar indagar sobre la presencia de los estudios de género dentro de la geografía, nos encontramos con la obligación de analizar el feminismo, que es considerado como una concepción teórica, una práctica de interpretación $\mathrm{y}$, más que nada, un movimiento político. Un movimiento que va más allá de la academia, pues el diálogo con los discursos y las reivindicaciones sociales fue y es muy productivo, aunque eso no signifique que la tan deseada igualdad de género sea alcanzada (Veleda y Lan, 2007).

Por un lado, Montero (2006) concibe el concepto de feminismo como un movimiento social crítico que, a partir de su intervención concreta, se sitúa en permanente confrontación y diálogo con la realidad social y su propia evolución interna. En este proceso va a desarrollar su capacidad para examinar y poner de manifesto sus tensiones. Y por el otro, García (1989) conceptualiza a la geografía de o del género o geografía feminista como aquella que se interesa por la comprensión de las interrelaciones que existen entre las relaciones de género -que son una construcción social-y los diferentes entornos que, en la mayoría de los casos, son también construcciones sociales.

Es por ello que para Veleda y Lan (2007) los estudios de estos movimientos apuntan a una mirada más específica, que busca la heterogeneidad a través de un análisis empírico y cualitativo, que identifica a los sujetos involucrados en el movimiento, sus prácticas y sus objetivos. Esto no significa desconsiderar las restricciones estructurales y coyunturales sufridas por estos sujetos, donde sus objetivos de transformación obligan a actuar en el terreno de las ideas a fin de subvertir arraigados códigos culturales, normas y valores, así como el sistema simbólico de interpretación y representación, que hace aparecer normales comportamientos y actitudes sexistas, -que privilegian lo masculino y las relaciones de poder patriarcal- (Montero, 2006).

De esta manera y de acuerdo con Baylina (2016), la geografía feminista es la que incorpora las aportaciones teóricas del feminismo a la explicación e interpretación de los hechos geográficos. A partir de ahí pretende analizar la relación entre las divisiones de género y las divisiones espaciales para descubrir cómo se constituyen mutuamente (Baylina, 2016). De tal modo, surgen a la par y desde la esfera feminista, los movimientos por la reivindicación pública, no solo 
de los derechos femeninos, sino de las disidencias sexuales, donde las amplias necesidades del sector homosexual también se ven manifestadas a través de la implantación de evidentes desigualdades en el espacio urbano, generadas por las relaciones de género y por los roles ortodoxos a los que eran sometidos por el contexto patriarcal.

Estos cambios propiciaron no sólo transformación de mentalidades, sino también en el espacio urbano (Veleda y Lan, 2007). Por lo tanto, la geografía del género puede considerarse la respuesta académica al auge del movimiento feminista de los años setenta (Baylina, 2016), ya que el género es una categoría de diferenciación social reconocida en la geografía desde los años ochenta (a pesar de que algunos artículos importantes ya fueron escritos en los setenta (Baylina, 2016). Además, la incorporación del enfoque del género al estudio de cuestiones geográficas enriquece el debate sobre los procesos de ocupación y organización del espacio, al sumar miradas desde ángulos no siempre visibles (Gómez, 2012). Sin embargo, Townsend (2002) asegura que la institucionalización del feminismo ha significado la pérdida del proyecto político emancipador, por ello es necesario que la propuesta feminista recupere su interés por vincularse con la vida cotidiana, con la producción de información de base y con el trabajo cooperativo.

En este contexto de incertidumbres políticas y académicas, estas nuevas prácticas sociales provocan nuevos desafíos para las ciencias sociales y humanas (Veleda y Lan, 2007). Igualmente, la comparación de estudios de género en distintos contextos históricos, geográficos y sociales (por ejemplo, de clase) nos muestra cómo feminidad y masculinidad son construcciones sociales, y nos ayuda a captar los diversos elementos que la componen (Karsten y Meertens, 1991). Por lo que es importante comprender que los movimientos de mujeres o movimientos feministas - que no son necesariamente compuestos sólo por mujeres- se transforman en movimientos sociales activos cuando identifican formas de opresión que extrapolan las relaciones de producción y abarcan cuestiones más amplias como la violencia, el medio ambiente, la calidad de vida, la cultura patriarcal, las desigualdades de género y otras que cuestionan los actuales paradigmas sociales (Veleda y Lan, 2007).

Así es claro reconocer que estos avances son significativos, aunque entendemos que aún necesitamos de iniciativas por parte de las instituciones académicas y de las asociaciones de geógrafos y geógrafas que incentiven y acompañen el proceso de desarrollo de los estudios de género en la geografía (Veleda y Lan, 2007). Dado que se debe hablar de una geografía en general de o del género y no limitadamente feminista porque la geografía del género o geografía feminista - denominación que también recibe- va mucho más allá que la denominada "geografía de las mujeres", interesada simplemente en poner de relieve las actividades femeninas y sus repercusiones en el espacio (García, 1989). Y como bien señala García (1985) la geografía feminista no tiene por qué ser cultivada solo por mujeres o centrarse exclusivamente en ellas, ya que los 
enfoques feministas más prometedores son aquellos que engloban los roles de género asignados tanto a mujeres como a hombres.

\section{Geografía de la(s) sexualidad(es)}

Entre las "nuevas" líneas de investigación están las prácticas sexuales que hasta hace poco tiempo eran consideradas inaceptables dentro de los códigos de conducta de la sociedad heteronormativa (Dóniz, 2015). Aún hoy es muy difícil hablar de estos temas en la geografía (y en otras disciplinas de las ciencias sociales) en que la censura está a la orden del día, porque temas de investigación similares siguen siendo objeto de discriminación por parte de docentes que piensan que solo le atañen a un reducido grupo de personas marginalizadas, y porque todavía encontramos múltiples casos de violencia contra portadores de VIH-SIDA, con políticas mudas y exangües a las realidades sociales de los principales afectados (Ramírez, 2013).

A pesar que de los geógrafos han prestado especial atención a la espacialidad de la sexualidad, es decir, cómo se organiza y se da significado a la sexualidad especialmente a través de la praxis (Elder et al., 2003), es evidente que, la investigación sobre la geografía urbana de la sexualidad crea cierta incomodidad entre los estudiosos (Ruiz, 2012), ya que, temas sobre sexo implica repensar la posición del geógrafo en la academia y en el trabajo de campo (Ramírez, 2013). De esta manera, el sexo como discurso puede actuar como una variable de espacialización homonormativa y moral, que distingue lo permitido de lo prohibido en el espacio público (Ramírez, 2013).

La dinámica de la sexualidad en la Geografía ha sido estudiada a través de los autores: Dóniz, 2016; Langarita, 2014; Ghisyawan, 2014; Ruiz, 2012; Cattan y Vanolo, 2011; Ferreira, 2010 y Elder et al., 2003. Mayormente las investigaciones relacionadas con el sexo y la geografía en países en vías de desarrollo son los de Bruciaga, 2018; Espinosa, 2017; Simonetto, 2017; Ramírez, 2013; López y Sánchez, 2004. Por lo que se puede considerar que dentro del estudio de la geografía de las sexualidades existen básicamente tres elementos presentes: sexualidad, espacios o lugares y erotismo.

Junto con Brasil, México es uno de los países latinoamericanos en el que más investigaciones académicas realizan sobre sexualidades, con especial hincapié en las masculinidades homoeróticas y sus intersecciones con las masculinidades heterosexistas o heteronormativas (López y Van, 2013). En cualquier caso, muchas de las investigaciones sobre geografía y sexualidad están incompletas y se presentan con el apellido de aproximaciones cualitativas, por lo que el reto futuro debe ir encaminado a mejorar o plantear nuevos métodos tanto para su estudio cualitativo como cuantitativo (Dóniz, 2015). Aunado a que algunos artículos y libros sobre la articulación entre sexualidad y geografía se quedan cortos en cuanto al sexo como práctica espacial (Ramírez, 2013). Esto debido a que, las investigaciones sobre la sexualidad invaden una faceta muy privada de 
los individuos, por lo que su estudio entraña ciertas dificultades a la hora de obtener la información (Dóniz, 2016).

Según Ruiz (2012) no fue sino hasta la década de los sesenta cuando se organizó un movimiento LGBT de base urbana en torno a la noción de liberación radical. La "liberación" fue la reacción contracultural a la opresión generalizada de lesbianas, gais, bisexuales y transexuales. El propósito de la liberación era emanciparse de los estigmas internalizados y abrazar la sexualidad como parte de un orden natural, con lo cual el coming out o salida del clóset, fue una proclamación pública de la sexualidad, en tanto una afirmación de la individualidad como un pronunciamiento de la diferencia (Ruiz, 2012).

Partiendo de la afirmación de López y Sánchez (2004) -establece que la ciudad se constituye por distintos lugares que son transformados en espacios cuando se les atribuye un significado y sentido por parte de la sociedad-los lugares fueron erigidos dentro de la trama urbana con un fin específico pero, al paso del tiempo, la sociedad les destina otros usos. Se debe considerar que la ciudad, sus espacios y sus tiempos, deben dar cabida a la complejidad y diversidad de la vida humana. Sin embargo, la organización material y simbólica de la sociedad, basada aún en la relación de los sexos, tiende a negar esta experiencia de vida múltiple (Quintero y Fonseca, 2008).

Dos temas que están interrelacionados - pero que no son exclusivos- en el análisis de la geografía y la sexualidad es el cruising y el deseo entre hombres que tienen relaciones con otros hombres -sean éstos identificados o no con una orientación sexual o identidad de género homosexual-. Porque la cuestión es que es difícil saber quiénes se identifican como gais, bisexuales o heterosexuales en un espacio en el que apenas se habla y en el que el interés por el anonimato es uno de los principios de la organización. De hecho, construir su identidad a partir de la práctica sexual es una cuestión menor para aquellos que no han salido del armario o que se declaran heterosexuales en las zonas del cruising (Langarita, 2014). Ya que para aquellos que se niegan a expresar su identidad homoerótica conceptualizan que lo que sucede en casa es privacidad y ensimismamiento, en la calle es apertura, fluidez y vida pública (Quintero y Fonseca, 2008).

Aunque se debe tener en cuenta que, precisamente, los estudios sobre diversidad sexual convergen con la teoría queer, al reconocer la movilidad y el carácter no fijo de las identidades sexuales (López y Sánchez, 2004). Sin embargo, es claro que una persona que está en la zona de cruising, que se considera gay y mantiene relaciones sexuales con otros hombres, no genera ningún conflicto consigo mismo entorno a su identidad sexual, se presenta coherente entre su identidad y su práctica sexual (Langarita, 2014).

Por tanto, es importante conceptualizar sobre qué es el cruising y cómo son los lugares para ésta actividad. Desde la concepción de Ramírez (2013) el cruising es la búsqueda consciente de relaciones sexuales efímeras, anónimas y casuales con personas en ambientes públicos o en espacios privatizados, diseñados para estos fines. De acuerdo con Langarita (2014), las zonas de cruising son espacios de 
"ligoteo" de baja exigencia, en la medida en que no es necesario arreglarse, ni de una inversión económica para la satisfacción de los deseos sexuales desconocidos. El tipo de ropa de los usuarios, a diferencia de otras zonas para interacción sexual, como bares o discotecas, no suele ser objeto de interés para el resto de los participantes. Las personas acostumbran ir con ropa de calle, sin arreglar o incluso con la ropa de trabajo.

De tal modo, se debe hablar claramente de deseo y no de prostitución gay (este sería en cuestión de otro tema) debido a que su práctica no requiere del intercambio de sexo por dinero. A diferencia de este, por un lado las zonas de prostitución están bien ubicadas, no son intercambiables y se dan en ambientes más limitados, y por el otro, porque según Bruciaga (2018) la verdadera identidad del urbanismo gay alrededor del mundo se encuentra en las zonas de cruising y no en los barrios reconocibles por las banderas de arcoíris y los éxitos pop que suenan mal ecualizados. Aunado a que no es posible construir un perfil de usuario claro, definido y estable de zonas de cruising, porque existen diversos factores que se sobreponen los unos a los otros y que combinados pueden dar lugar a un sin fin de resultados (Langarita, 2014).

Se entenderá, entonces, que hablar de relaciones sexuales anónimas consensuadas entre hombres que tienen sexo con otros hombres no pertenecerá a la categoría de prostitución homosexual masculina. Dado que el trabajo sexual es un ritual desempeñado por el sexoservidor y el cliente, que inicia con el primer contacto visual o auditivo (en el caso de la comunicación telefónica) y concluye cuando se despiden (López, 2013). Lo cual, para el caso del cruising, no existe inmediación alguna de intercambio de información que pudieran exponer la identidad de alguno u otro y tampoco para seguir en contacto, porque no se busca la "remuneración más alta posible" sino la producción del deseo concretado en satisfacción mutua y consensuada fuera de la idea del comercio sexual.

Partiendo de la idea de que, el sexo es espacial y no puede reducirse su estudio a una mera cuestión de ubicación en un mapa de los lugares de cruising entre hombres, de los bares de striptease, de los circuitos de prostitución en las calles, de los clubes de swingers o de otras prácticas similares (Ramírez, 2013). Se trata, pues, de que con el análisis geográfico se favorezca el surgimiento y la exposición de sexualidades diversas, tratando de insertarlas al espacio de un modo más natural, $y$ válido, que otorgue sentido a la emancipación social y cultural de los procesos adaptativos y de apropiación de los espacios para las prácticas sexuales.

Además, en este sentido está claro que es necesario plantearse dónde están, pero también por qué son elegidos unos lugares y no otros, quiénes los visitan, por qué acuden a ellos, cómo conviven con otros usos en los mismos espacios, qué potenciales conflictos entre usuarios hay, etc. (Dóniz, 2016). Desde esta perspectiva es posible conocer, interpretar y discutir las vinculaciones existentes entre las relaciones de género socialmente construidas y el espacio urbano socialmente producido. Ello implica reconocer también que las relaciones de 
género se construyen y modifican dentro de determinados espacios, que varían en el tiempo y según los distintos lugares de las ciudades y entre las ciudades (Quintero y Fonseca, 2008). De no ser así, se cae en el error de que con el silenciamiento del sexo como espacio válido y central del análisis geográfico y sociocultural se promueven múltiples formas de coerción y regulación que ocultan cómo su ejercicio produce espacios y cuerpos, construye ciudades, transforma paisajes, delinea subjetividades (como la de investigador), llena de sentido los lugares, favorece la creación de sexualidades alternativas y confronta el gobierno de las poblaciones (Ramírez, 2013), porque es evidente que lugares de cruising cargan con signos de perversidad y abyección heredados de discursos morales judeocristianos que aún hoy ven con ojos de pecado y reprobación las prácticas sexuales fuera de la constitución de la familia heterosexual, monogámica y reproductiva (Ramírez, 2013).

Por tanto, la experimentación sexual entonces podrá ser traslada al espacio públicos debido a la apertura cultural que los gais experimenten dentro de "ciudades permisibles", porque ahora no solo la identidad está puesta en expresión pública sino también el sexo, la sexualidad y el erotismo que invaden las calles, los espacios de esparcimiento, de recreación, comerciales, etc. Estas relaciones sexuales perpetuadas en espacios tanto públicos como privados crean una organización sexual no comercial, a través de factores sociales, políticos y espaciales que se encuentran interrelacionados en lo urbano y que son sitios atractivos y funcionales utilizados para la consolidación del fin último del sexo: el placer homoerótico; y que además con esto, el colectivo gay busca arraigarse al identificarse como una entidad sociopolítica diferente, en sus manifestaciones espaciales. De tal modo, se puede hablar de espacios sexualizados u homosexuales.

Se determina entonces, como bien la afirma Ramírez (2013), que el sexo, sin lugar a dudas, es una variable espacial, porque su construcción social se da con la formación de escenas que son consolidados en territorios sexuales que se ofrecen para el establecimiento e identificación única y exclusiva de la intimidad. De tal modo existe una relación fortuita con el espacio para el sexo público, desde una lógica radical, "torcida" e irreverente, en el que el objetivo es precisamente esa búsqueda y concreción del acto sexual sin una identidad fijada y tampoco reducida. Así estos actos sexuales que producen espacios son conducidos hacia experiencias desde distintos lugares, donde la necesidad sexual del individuo se vuelve transitoria abarcando un carácter anónimo, sin culpabilidad y bajo criterios flexibles de disponibilidad, es decir, en la que se construyen espacialmente relaciones sociales eróticas con movilidad o, en otras palabras, el surgimiento de una construcción social radical del espacio público y una "solidaridad" por el deseo. A esto le denominaremos geografía de la sexualidad. 


\section{Geografía de la diversidad}

En la actualidad, la diversidad sexual es un tema ampliamente debatido en los medios de comunicación, pero poco tratado en la academia. Se puede ver una cierta discusión sobre el tema en algunos estudios antropológicos, o áreas relacionadas con el género y la sexualidad, sin embargo, la geografía también puede hacer una contribución en este tema al vincular las cuestiones de género a la producción del espacio y la formación de los territorios (Vasconcelos, 2010), porque ésta tiene dentro de sus cualidades el poner atención en la interacción, producción y transformación de las sociedades con su territorio, en donde éste último no actúa únicamente como escenario de la vida humana, sino que es además productor de significados relacionados al habitar y la ocupación del espacio en múltiples términos y dimensiones (Fuentealba, 2016).

Las relaciones territoriales son objeto de estudio de múltiples ciencias interesadas en descifrar las diversas influencias y efectos derivados de sus connotaciones sociológicas, culturales, históricas, económicas, socioambientales, comerciales y políticas. Se agrega la geografía como ciencia interesada en el estudio de las interrelaciones que se suceden en el espacio geográfico entre unas sociedades y territorios que interactúan, y ese escenario es el sustrato de las relaciones territoriales (Aché, 2012).

Los individuos y la colectividad actúan sobre los espacios en su creación, evolución y mantenimiento. Toda participación se adscribe en el desarrollo de estrategias particulares y objetivas que llevan al ordenamiento del territorio. El ordenamiento del territorio trata de sustituir lo irregular, lo discordante y lo fuera de orden que ocurre en el espacio geográfico para lograr una participación más sistemática y a su vez unitaria (Aché, 2012). Sin embargo, es importante destacar que el territorio también presenta contradicciones. Estas contradicciones aparecen, pues ese territorio, al mismo tiempo que reúne e integra a esos individuos, los segrega del resto de la sociedad (Vasconcelos, 2010). Lo cual este pensamiento es discordante, confuso y subjetivo porque dichos objetivos no están encaminados a la inclusión sino a la homogenización, cuestión que es injusto desde el enfoque de la geografía de la diversidad.

Las geografías de las sexualidades se centran principalmente en las experiencias vividas y las negociaciones de identidad sexual de hombres gay y mujeres lesbianas en una sociedad basada en divisiones binarias de sexo, género y sexualidades (Maliepaard, 2015), por lo que indudablemente, los espacios urbanos están asociados con las características que crean posibilidades de desarrollo para las subculturas que se centran en las políticas de identidad y la apropiación del espacio (Ghinea y Manea, 2014). Así, es interesante que ambos estudios reconozcan que la vida nocturna de gais y lesbianas también debe entenderse como espacios sueltos y riesgosos donde la presión social hace que los jóvenes gais y lesbianas sean inciertos (Maliepaard, 2015).

Los aportes de la diversidad en la Geografía son los de autores como: Maliepaard (2015), Ghinea y Manea (2014), Vartabedian (2012), Vasconcelos 
(2010), O'Riordan (2005), Santos (2003), Aronovich (s/a). Además, dos interesantes estudios relacionados con la diversidad y la geografía en América Latina son los de Fuentealba (2016) y Luna (2011). Así se puede establecer que en el estudio de la geografía de la diversidad intervienen al menos tres bases conceptuales: género LGBTTI, territorio, e identidad.

En primer lugar, las normas sociales se traducen en reglas de comportamiento espacial acerca del control del cuerpo, de las afectividades y del deseo disidente, en tanto la forma de subvertir el peso de la sociedad heteronormada es a partir de la conciencia de los derechos, en este caso el derecho a existir y a aparecer (Fuentealba, 2016). Generalmente, la disidencia es un atributo de las personas que sirve para definir a las que se apartan de los caminos ortodoxos o mayoritarios (Santos, 2003). De tal manera, que las disidencias son tratadas como exclusiones y, como tales, son marginalizadas: "fuera del sistema sólo permanece quien quiere" (Santos, 2003). Significa que, dentro de los contextos sociales, se crea una exclusión encaminada a una marginación debido a las dinámicas no integradoras que funcionan como elementos diferenciadores de las identidades disidentes. Así, la formación de la comunidad LGBT está estrechamente conectada con la idea del espacio limitado (Ghinea y Manea, 2014).

La comunidad lesbiana, gay, bisexual, travesti, transexual, transgénero, intersexual y queer (LGBTTTIQ) es aquella constituida por individuos disidentes, con enfoque radical, que centran su espacialidad en dinámicas justas y no ajustadas dentro de los territorios normados. Se entiende por comunidad LGBTTTIQ a aquellos grupos de la diversidad sexual que están fuera del contexto de la heterosexualidad y que buscan forjar mejores condiciones de vida, de aceptación, visibilidad y legitimación colectiva, sin embargo, dado su condición de distinciones y variabilidades genéricas, también tienen conflictos dentro de sus mismos territorios de convivencias.

En palabras de Ghinea y Manea (2014), consideremos la instancia del espacio público como el área discursiva de la batalla entre diferentes intereses. Un resultado de tales debates sería que los límites entre los lugares públicos en una ciudad (propiedad de la comunidad y regulados) y las áreas privadas están en un cambio continuo. El espacio está, por lo tanto, fragmentado por las relaciones de poder y dividido en lugares. Y, en cualquier caso, la homosexualidad, así como otras formas de expresar y vivir la sexualidad, se convierte en disidencia al poner en cuestión, por lo menos de entrada, la existencia misma del género y de sus relaciones, y, en consecuencia, algunas de las instituciones sagradas del capitalismo, fundamentalmente el patriarcado (Santos, 2003).

El no encajar precisamente en los estándares que la sociedad -ligada a diferentes instituciones como el estado, la religión o la familia- espera de sus ciudadanos, se traduce muchas veces en la preferencia de las personas identificadas con un género o sexo que escapa a la norma, por participar en espacios homosexuales, de disidencia o incluso de resistencia, con el fin de visibilizarse y sociabilizar de forma libre, aunque esta libertad implique también 
la preferencia por el ocultamiento y clandestinidad de las propias prácticas (Fuentealba, 2016).

Este contraste simultáneo hace que estos territorios de convivencia homosexuales acaban recibiendo el estigma del prejuicio de que estos individuos sufren, donde muchas personas se niegan a permanecer en estos lugares por temor a ser asociados con esta identidad, lo que refleja el prejuicio que existe incluso en nuestra sociedad (Vasconcelos, 2010). A pesar de que la homosexualidad mantiene una gran capacidad de disidencia (Santos, 2003).

Iniciando con la afirmación de Vasconcelos (2010) de que los homosexuales, como grupo, dotados de identidad propia, son capaces de formar territorios y territorialidades a escala local, por tanto, se requiere que hoy en día, se comprenda el sentido de la capitalización de forma consciente de que la las personas LGBT necesitan que sus espacios, que por mucho tiempo han sido adecuados e intervenidos, sean reconocidos como propios (Luna, 2011). No obstante, los espacios dentro de la misma comunidad LGBTTTIQ pasan a ser excluyentes en algún sentido, ya que tenemos espacios netamente para gais, otros para lesbianas, donde no puede haber una interacción directa entre estos grupos, como también en la mayoría de los casos, con una cultura dentro de la misma comunidad se imparten mecanismos para compartir el espacio (Luna, 2011).

Por su parte, hablar de sujetos queer, o subjetividades queer, es discutir acerca de las identidades que transgreden la heteronormatividad y cuya sola orientación sexual parece ser suficiente para marcar diferencias respecto a las vivencias y percepciones sobre el espacio público, Determinando maneras de actuar, de expresarse o de transitar, dejando en evidencia tensiones, desigualdades y conflictos de un espacio en permanente construcción y transformación (Fuentealba, 2016). A pesar de que el propósito político de la teoría queer intenta desestabilizar las taxonomías heterosexuales, situando a todos los que practican sexualidades alternativas en este grupo disidente, hasta ahora ha persistido una infraestructura genérica de carácter patriarcal que ha otorgado especificidades distintas, tanto a nivel de lo subcultural como en las recientes asociaciones políticas (Guerra, 2011).

Asimismo, este estudio geográfico que también ha abarcado a los migrantes queer ha permitido visibilizar otros problemas de orden territorial como los movimientos migratorios y de los que existen limitados estudios. Por ejemplo, Aronovich (s/a) destaca que la migración queer no es un fenómeno nuevo en la mayoría de los casos, y las comunidades más bien establecidas ofrecen servicios sociales y apoyo para sus miembros, lo que también podría ser una razón para que las personas LGBTTTIQ prefieran mudarse a una comunidad existente, en lugar de crear nuevas comunidades. Ya sea en entornos rurales o en centros urbanos que son menos conocidos por su apertura hacia las minorías sexuales.

Igualmente, la geografía de la diversidad ha contenido a la migración travesti. Como bien la afirma Vartabedian (2012), las migraciones de las travestis no solo 
pueden ser pensadas como una huida, sino también como una forma de encontrarse así mismas y decidir enfrentar con todas sus consecuencias la vivencia plena de sus identidades de género. Un lugar "favorable" para que estas identidades puedan desarrollarse combina: a) un entorno social lo menos homofóbico $\mathrm{y} / \mathrm{o}$ transfóbico posible, aunque sea difícil que se sientan completamente seguras al transitar por determinados territorios, al menos es importante que identifiquen un sitio donde sus vidas no corran peligro; b) la libertad de vivir sus sexualidades y travestilidades sin opresiones familiares (Vartabedian,2012).

En cuanto a la bisexualidad, Maliepaard (2015) señala que éste tiene la opción de causar "problemas de género" y cuestionar la interconexión entre la sexualidad y el género; por lo tanto, tiene el potencial de desafiar la monosexualidad obligatoria y el discurso heteronormativo que gobierna la política sexual contemporánea, el deseo y la sociedad (Maliepaard, 2015). Ya que los espacios bisexuales trazan una geografía histórica de las comunidades bisexuales, lesbianas, gais y transexuales y la movilización (O'Riordan, 2005). Asimismo, la identificación de espacios bisexuales también podría resaltar la temporalidad de la codificación sexual de los espacios que tiene un valor más amplio, más allá de la comunidad bisexual (Maliepaard, 2015).

Desde la geografía de la bisexualidad, como la ha llamado Maliepaard (2015), sirve un interés académico y social para identificar los espacios bisexuales y articular su existencia viendo la interdependencia de las identidades, las negociaciones de identidad y los espacios. Finalmente, conceptualizar los espacios bisexuales como estabilizaciones espaciotemporales de las prácticas bisexuales (incluidas las lingüísticas), no solo es útil para deconstruir el funcionamiento del sistema binario de sexualidades (incluidos sexo y género), sino también para identificar hogares bisexuales y tal vez, incluso, paraísos seguros (Maliepaard, 2015). Podemos pensar en una sociedad igualitaria donde se respetan todas las identidades y donde los territorios como los de convivencia homosexual no sirvan más como un refugio, como escondite, sino como un lugar de convivencia pacífica, donde todos circulen sin miedo a lo diferente, y principalmente, que esta diferencia se respete también fuera de esos territorios, no habiendo más exclusiones, ni discriminaciones (Vasconcelos, 2010).

Lo importante para erradicar esta situación sería, como bien lo señala Ghinea y Manea (2014), trabajar en conjunto sobre el tema de "ciudadanía urbana", que mejoraría la calidad de vida de los residentes urbanos. Asimismo, resulta necesario llevar la discusión y el interés por las problemáticas de la ciudad fuera del espacio académico y especializado, puesto que el espacio se produce colectivamente entre diversos actores sociales, y donde además, el conocimiento no es de uso exclusivo del trabajo disciplinar (Fuentealba, 2016), porque los espacios públicos, cuando son tomados por grupos marginalizados como espacios para la representación, ganan en importancia política (Santos, 2003). 
Además, no hay que olvidar que el espacio de los geógrafos no es solamente una extensión natural, donde la naturaleza se constituía en la base fundamental del estudio geográfico, también adquiere un enfoque funcionalista basado en tres tipos de redes: sociales, de convivencia y de establecimiento humano; y finalmente comprende el enfoque cultural donde la sociedad ocupa, transforma, construye y ordena el espacio (Vargas, 2012).

De esta forma, la interacción de las personas LBGTTTIQ con los espacios urbanos y el contacto con los espacios heteronormados están interrelacionados en el imaginario público, existiendo límites y restricciones temporales que surgen de mediaciones patriarcales, producto de una connotación subjetiva y derivada de los constructos históricos y culturales que las urbes han heredado y dimensionado en la vida pública y privada de los disidentes sexuales.

\section{Aportes acerca de los espacios de sociabilidad gay desde la perspectiva geográfica en América Latina}

La homosexualidad masculina con el espacio ha constituido una relación indisociable en su dinámica, lo cual se ha establecido en lugares de sociabilidad, interés, recreación, comerciales, esparcimiento, diversión, entre otros. Estos lugares han sido estudiados desde distintos enfoques dentro de la geografía. Así, la espacialidad gay ha sido analizada a través del turismo gay, turismo sexual y prostitución gay, y marketing gay.

Del primero se encontraron estudios de Woolfok et al., 2016; Tamayo y Sophie, 2015; García y Marín, 2014; Marín, 2012 y Monterrubio, 2008. En cuanto al segundo se ubicaron los de: Vargas y Alcalá, 2015; Arroyo y Amador, 2015; Mendoza, 2015; López y Van, 2013; Bringas y Gaxiola, 2012; López y Carmona, 2008; Vargas y Alcalá, 2008. Y por último se hallaron los estudios de: Regalado et al., 2018; Reyes, 2017; Islas, 2013; Del Muro et al., 2012; Zarur, 2011; Poveda y Ávila, 2008; y Moner et al., 2007.

En cuanto a la noción de turismo gay y de la diversidad, (Woolfok et al., 2016) afirman que el turismo LGBTTTIQ es una modalidad de la actividad turística que surge para satisfacer las demandas de un mercado específico, aporta al ingreso per cápita en virtud de que genera empleo y capta divisas. A pesar de lo anterior, de su crecimiento exponencial y de la presión que ejerce en los estados y en los requerimientos del mercado, el turismo LGBTTTIQ es víctima de diferentes formas de discriminación y exclusión social, por lo que es necesario realizar una serie de transformaciones socioculturales y políticas que modifiquen la forma en la que se asume la diversidad sexual y de género dentro del concepto "desarrollo". Así, el turismo homosexual se concentra fundamentalmente en tres tipos de destinos: sol y playa, city-breaks y eventos (Moner et al., 2008).

En cuanto al turismo sexual, López y Van (2013) conceptualizan que en el planteamiento de que el turismo homosexual/queer es una especie de turismo de sexo, se sugiere que parte de la construcción de las identidades homoéroticas, 
especialmente la gay, se relaciona con frecuentes experiencias sexuales, por lo que en las vacaciones de estos individuos el sexo toma un peso aún mayor, y a veces el único. Por su parte, el marketing gay o "mercado rosa" se trata de un segmento interesante y rentable para distintos tipos de empresas y organizaciones del sector turístico por su comportamiento de consumo turístico y por su poder adquisitivo (Moner et al., 2008).

En cuanto a la concepción de espacio público como elemento de división socioespacial, podemos ubicar diversas investigaciones que analizan las dinámicas de la población gay insertos en la ciudad, cuyos actores divergentes buscan legitimarse y constituirse a pesar de las evidentes restricciones territoriales que les devienen del orden heterocentrista, ya que los homosexuales masculinos están en una constante lucha por visibilizarse en el espacio público, porque este espacio es un instrumento por excelencia de identidad social. De tal modo, se presentan algunos estudios publicados en Latinoamérica, básicamente en México y que vinculan la espacialidad gay masculina, desde la concepción de los lugares de sociabilidad gay o interés.

Los estudios acerca de los lugares gais en México tienen sus inicios en décadas recientes aunque el fenómeno en sí no sea algo nuevo. De acuerdo al estudio de Boivin (2013), es a finales de 1940 cuando aparecen los primeros lugares comerciales especializados para el segmento gay y lésbico. En palabras de Boivin (2013): "La aparición de estos primeros comercios especializados supone una evolución importante en los modos de vida de los homosexuales de las clases medias de la ciudad de México, destacándose su mayor separación de las clases populares en los lugares de ocio".

Es decir, al tiempo que se logra un avance significativo desde la construcción social de la identidad, éste a su vez se establece inevitablemente bajo una fragmentación espacial, constituyendo una segregación social del mismo colectivo diferenciada en desigualdad de clases. Este sociólogo urbano conceptualiza estos sitios como "lugares de homosocialización". En su escrito titulado De cantinas, vapores, cines y discotecas. Cambios, rupturas e inercias en los modos y espacios de homosocialización de la ciudad de México, Boivin (2013), establece su investigación mediante el análisis de fuentes documentales, entrevistas y biografías de personas homosexuales que fueron militantes en el periodo de 1940-1970, a fin de lograr cubrir la "escena" histórica de las resignaciones espaciales de aquella época.

Descubre, por ejemplo que los baños de vapor en esa época facilitaban el encuentro entre varones. Además, llega a la conclusión de que, tanto en los años veinte y treinta como en los años cincuenta y sesenta, por muy estigmatizadas que fueran las relaciones sexuales entre varones, los homosexuales no dejaban de ser visibles en el espacio urbano (Boivin, 2013). Y, a pesar de todas las restricciones (Boivin, 2013b), asegura que en los años sesenta y principios de los setenta, se acrecienta la división social del espacio de homosocialización. 
Por su parte, Laguarda (2010) en su trabajo El ambiente: espacios de sociabilidad gay en la ciudad de México, 1968-1982, mediante crónicas y entrevistas a personas que a finales de los sesenta y principios de los años ochenta tuvieron acceso a los espacios de identificación gay de dicha época, consiguió incorporar, al igual que Boivin (2013), elementos trascendentales a la historia de los espacios de recreación y entretenimiento que no habían sido registrados antes, así como la epidemia del sida, por el surgimiento de éste en dicho periodo.

Pero además expuso la conceptualización del término "ambiente" para referirse esa dinámica espacial que conducía a los homosexuales a esparcirse y emanciparse. Llegando a la conclusión de que la apropiación de la identidad gay en la ciudad de México tuvo como soporte la socialización producida dentro de los círculos homosexuales y, especialmente, dentro de los espacios de sociabilidad específicamente establecidos para los gais - los nacientes bares-a partir de la segunda mitad de la década de los setenta (Laguarda, 2010).

En la investigación titulada Lugares gays en la Ciudad de México y su relación con la construcción de identidades de Sánchez (2004), mediante la teoría de la construcción social y la difusión, así como la utilización de los marcos conceptuales de identidad, gay y queer, este geógrafo logró analizar los patrones territoriales de los espacios gais, su relación, diferenciación y la construcción de esas identidades sexo-genéricas del siglo $\mathrm{xx}$, determinando que las condiciones de visibilidad y territorialidad junto con otros aspectos fisiológicos, psicológicos y socioculturales forman la identidad como concepto, enmarcada dentro de contextos espacio-temporales propios del lugar donde se desenvuelve el individuo o la comunidad gay (Sánchez, 2004).

Otro estudio representativo es el de López y Sánchez (2004) titulado El estudio Dinámica territorial del deseo queer en Monterrey donde a través de entrevistas con personas pertenecientes de la diversidad, los autores muestran cómo los espacios sexuados fungen como elementos esenciales para la relación socioafectiva, cuyo dinamismo es eminentemente basado en el deseo del coito. Este vínculo erótico entre varones, logró que se pudiera describir de esta manera, los espacios queer existentes para este tipo de demanda en Monterrey. Así se llega a la conclusión de que muchos de los espacios que se revelan en este trabajo son clandestinos y se "esconden” del ámbito legal (López y Sánchez, 2004). Además, la mayor parte de los sitios del deseo que aquí se examinan se encuentran en un estado de deterioro marcado, en áreas proclives al peligro (zonas industriales, barrios en donde habitan estratos de la sociedad con bajos ingresos económicos), con olores desagradables muy marcados frecuentados por travestis que cobran (López y Sánchez, 2004).

En este sentido, igualmente vale la pena mencionar la investigación titulada Visión geográfica de los lugares gay de la Ciudad de México de Sánchez y López (2000), en la que se destaca el análisis de la interacción social de hombres gay de dicha ciudad, mediante observaciones y encuestas, en cuya investigación se logró 
tener un acercamiento de los patrones de socialización gay en los espacios públicos, así como del referenciación de los espacios. Asimismo, los hallazgos que presentan es que, los hombres homosexuales tienden a frecuentar un lugar particular en vez de acudir a diferentes lugares, una sola cantina, discoteca, estación del metro, parque, circuito de calles o café. Como resultado de ello no hay sitios gay que atiendan específicamente a gente nice o ejecutiva. Los hombres homosexuales de todos los estratos económicos se mezclan en los mismos lugares, comparten los mismos ambientes, peligros, relaciones sociales, publicaciones y demostraciones públicas (Sánchez y López, 2000).

La obra Jóvenes corazones gay en la ciudad de México. Género, identidad y sociabilidad en hombres gay de List (2017) presenta una exhaustiva investigación acerca de la dinámica espacial homosexual en lo urbano, cuyo trabajo se hizo a través de la observación participante, consulta de fuentes bibliográficas y novelas básicamente, en la que el autor halló que al hacer este análisis se pudo constatar que la identidad está construida a partir de múltiples planos. Los sujetos no tienen varias identidades como si se tratara de una esquizofrenia identitaria, sino que el sujeto puede interactuar en múltiples contextos sociales actualizando un aspecto de ésta. En este sentido, se planteó la construcción de planos identitarios en los cuales los sujetos pueden integrar diversas experiencias vitales y, de esta manera, actuar y participar de distintos ámbitos sociales (List, 2017).

Además de estos escritos, en la espacialidad gay se incluye el factor de la visibilidad en cuanto a sus contextos urbanos, de tal modo, aunado a la exposición de trabajos sobre los espacios de sociabilidad gay, se hace una reflexión acerca de los escritos que han incidido en la vertiente de visibilidad en cuanto al modelo socioespacial de los lugares para las dinámicas gais.

El trabajo denominado De la marginalidad de la homosexualidad a su visibilización en Xalapa 1969-2005, de Barffusón (2016), donde se destaca la presencia pública en la actualidad de la homosexualidad en la ciudad, como parte de un proceso no estático y de continuos cambios. De esta forma el autor mediante entrevistas a profundidad logra exponer sus conclusiones destacando que, el estado actual de la visibilización homosexual en Xalapa va más allá de los espacios de interacción homosexual, se puede decir que es perceptible en el cuerpo social, no así su actuación. Es decir, hace falta una mayor presencia y participación en acciones de índole social, políticas, artísticas y culturales que contribuyan a generar condiciones más allá de la diversión. Los procesos de cambio cultural, como el que se considera está sucediendo en Xalapa con la visibilización de la homosexualidad masculina, no son procesos continuos, homogéneos, lineales, sin conflictos; más bien se trata de una comprensión de las permanencias, cambios y tensiones como partes constituyentes de este proceso (Barffusón, 2016).

En el escrito Visibilidad gay y espacio público en la capital de Aguascalientes: romper para entrar o entrar para romper de Bobadilla (2013), desde la 
representación de los avances, el autor señala que al menos en los ambientes urbanos, los sujetos gais han logrado reconceptualizarse y forjar su identidad de una manera más positiva, ya que estos jóvenes universitarios se presentan menos sensibles a temas de género e identidad homosexual, esto gracias a las historias de vida y testimonios, y dado que a los sujetos de estudio se les ha impartido cursos de formación humanística, esto influyó también en su percepción en cuanto al tema.

El autor concluye afirmando que como parte vital de las prácticas performativas que accionan los sujetos gay en sus procesos de interacción, la visibilidad en el espacio público, vista como instrumento de legitimación social de una identidad transgresora, o como toma del espacio para la manifestación y expresión de la misma, representa uno de los eslabones más importantes en la conformación de los imaginarios sociales alrededor de la diversidad sexual y una de las mayores conquistas en el plano de los derechos humanos (Bobadilla, 2013).

Por su parte el autor San Martín (2010), en su artículo nombrado Visibilidad de la comunidad gay y lésbica en el espacio público de la Ciudad de México: La Zona Rosa, donde aborda la presencia espacial de hombres gais y lesbianas enfocándose en la explicación del modelo socioespacial constituido en la Zona Rosa, la cual está constituido por una interrelación de modelo integracionista, y comunitarista, el primero hace referencia al desarrollo natural de la diversidad con la heterosexualidad en conjunto, y el segundo se refiere a la generación de un espacio urbano específico para el desarrollo de la diversidad sexual.

En ese sentido, San Martín (2010) afirma que ambos modelos se complementan territorialmente para el caso de esta zona de estudio, así el autor finaliza aseverando que el modelo territorial que en la práctica se ha desarrollado en la Zona Rosa y barrios aledaños, muestra una posibilidad urbana "ecléctica", acaso mejor que otros modelos, y que al parecer ha funcionado para los gais, lesbianas y transexuales de México (San Martín, 2010).

Otro escrito acertado es La Visibilidad del homosexual, sus cartografías urbanas y la tolerancia del consumo, de Aluma (2012), en la cual se reflexiona acerca de la construcción del género y espacio urbano a través de la literatura gay más representativa mexicana y estadounidense, donde se hace alusión de los lugares que ha producido la comunidad gay a través de su historia a partir del siglo xx y hasta la actualidad. Según el autor, la tolerancia ha contribuido en la visibilidad tanto de los homosexuales, así como de sus espacios, aunque con ciertas restricciones. En su análisis, en cuanto al a homosexualidad urbana Aluma (2012) señala que esta urbe se manifiesta, en tanto criatura mutante, como el monstruo de múltiples cabezas que debe ser domado para poder subsistir en él, la fuente de la determinación para construir un nuevo proyecto de vida, el cimiento de nuevos microcosmos que buscan recrear la realidad física de otros destinos y otras culturas, inmersas o diseminadas en el interior y en las periferias de la misma. 
Y por último cabe destacar el texto ¿Un planeta fuera del armario? La visibilidad gay como objeto de estudio Geográfico, de Fernández (2007b), en la que básicamente presenta una metodología para medir el nivel de visibilidad gay en distintos países. El cual concluye señalando que la visibilidad gay, más allá de expresar los derechos conseguidos por determinados colectivos mejor o peor organizados y con mayor o menor capacidad de influencias en sus contextos culturales y políticos, puede ser considerada un indicador de gran interés para señalar los niveles de desarrollo alcanzados por las distintitas sociedades.

\section{Conclusiones}

Entre la espacialidad homosexual masculina vemos que los lugares gais y la visibilidad se hallan por excelencia en el espacio público, aunque no siempre este fenómeno se constituya de manera abierta o exclusiva, lo cual estos sitios son adaptados, constituidos y relativos para las dinámicas. La apertura de estos espacios para las distintas demandas y necesidades de este colectivo, ha logrado un desarrollo paulatino pero significativo de espacios dedicados a la recreación, diversión, sexo, comercio entre otros, cada uno con sus características distintivas. Es decir, en el presente análisis y mediante los diversos autores y sus investigaciones, se descubrió y comprendió la variabilidad de contextos que refuerzan la identidad gay en la ciudad, y que tanto los sitios como los individuos varoniles son funcionales, y performativos, según su condición, percepción y ubicación y grado de adaptabilidad social, por lo que la categoría de homosexual ha quedad corta y deformada para su connotación.

Cabe mencionar que el vínculo de los espacios gais con lo urbano requiere de un ambiente de tolerancia porque de ello dependerá su nivel de visibilidad, en el que la comunidad masculina -exprese o no una identidad de género homosexual- sienta un ambiente de respeto y no discriminación hacia sus prácticas sexo-genéricas en los espacios públicos. Conocer la apropiación de la homosexualidad, desde una perspectiva espacial y de acuerdo al performance de su identidad, podrá ayudar a un logro más objetivo desde las políticas públicas para un desarrollo e inserción del territorio de un modo menos estigmatizado, a fin de para prevenir y erradicar la segregación y fragmentación social del espacio.

Hasta ahora, el desafío pendiente es que, no podemos hablar de una Geografía esencialmente homosexual y mucho menos de una geografía de la homosexualidad masculina o gay, ya que este fenómeno aún sigue vinculado con el estudio del desarrollo de la geografía de género, por lo que es necesario des(enclaustrarla) de las demás geografías, para lograr su verdadera representatividad en la academia, esto si bien no debe inducir a una especialización del mismo, debe lograr analizar de manera minuciosa y central la espacialidad masculina, logrando generar estudios que vayan más allá de la simple descripción o queden poco cimentadas en cuanto a su enfoque teorético. 
De tal modo se requiere de una radicalización de los modos de hacer geografía, de que cada geógrafo no tenga prejuicio en manifestar y descubrir a los otros, en estudiar su comportamiento, sus dimensiones geográficas, así como sus procesos de socialización y apropiación, porque de ello dependerá en un futuro de las siguientes interpretaciones, así les recordaremos constantemente a los estudiosos que aún hay temas abordados, pero no terminados dentro del análisis geográfico.

\section{Bibliografía}

Aché, D., "Geografía de las desigualdades territoriales socio-económicas y socioambientales", en Terra Nueva Etapa, 37(43): 89-108, Caracas, 2012.

Aguilar, J., "Los espacios públicos y privados en Bogotá: hablando sobre la ciudad gay", ponencia presentada en el XV Encuentro de Geógrafos de América Latina, Bogotá, 2015.

Aluma, A., "La visibilidad del homosexual, sus cartografías urbanas y la tolerancia del consumo", en Revista de Humanidades, 25: 121-144, Ciudad de México y Nueva York, 2012.

Ayllón, M., “Investigación en España: la corriente del género en geografía”, en Universidad de México, 51: 552-553, México, 1997.

Apodaka, M., "Urbanismo inclusivo las calles tienen género", Eusko Jaurlaritzaren Argitalpen Zerbitzu Nagusia, Servicio Central de Publicaciones del Gobierno Vasco, Vitoria Gasteiz, 2012, 212 pp.

Aronovich, A., Migration - Queer Migration to urban Meccas, Masarik Univerity, Final Paper, República Checa, (Sin año) 16.

Arroyo, L. y Amador, K., "Turismo y trabajo sexual en Cancún”, en Estudios y Perspectivas en Turismo, 24(4): 982-992, Cancún, México, 2015.

Balbuena, R., Ovalle, L. y Villegas, C., “Organización política gay y espacio público”, en Trace, 63: 50-59, Centro de Estudios Mexicanos y Centroamericanos, Ciudad de México, México, 2013.

Baylina, M. "Evolución y aportaciones de la geografía de género", en Jornada La perspectiva de género en Geografía, Las Palmas de Gran Canaria, 2016, pp. 1-22.

Barffusón, R., De la marginalidad de la homosexualidad a su visibilización en Xalapa, Universidad Veracruzana, Xalapa, México, 2016, 184 pp.

Barrios, M. y Hernández, L., "Construcción de ciudad y políticas públicas frente a la segregación de la comunidad LGBTI", en 15avo. Encuentro de Geógrafos de América Latina EGAL-CUBA, Chapinero, 2015, 2-8 pp.

Bobadilla, J., "Visibilidad gay y espacio público en la capital de Aguascalientes: romper para entrar o entrar para romper", en Desacatos, 41: 123-138, Aguascalientes, 2013.

Boivin, R., "De cantinas, vapores, cines y discotecas. Cambios, rupturas e inercias en los modos y espacios de homosocialización de la Ciudad de México", en Revista Latinoamericana de Geografia e Gênero, 4 (2): 118-133, Ponta Grossa, Ciudad de México, 2013.

Boivin, R., "Formas de inclusión y exclusión de las minorías sexuales en la ciudad", Seminario Internacional Construcción de ciudad desde la diversidad, Bogotá, 2013b. 
__ "De la ambigüedad del clóset a la cultura del gueto gay: género y homosexualidad en París, Madrid y México", en La Ventana, 34: 146-190, México, 2011.

Bringas, N. y Gaxiola, R., "Los espacios de la prostitución en Tijuana: turismo sexual entre varones”, en Región y Sociedad, 55: 81-126, Tijuana, 2012.

Bruciaga, W., “'La cajita feliz', gays y urbanismo chilango: el tabú que nunca dejará de ser contemporáneo", en Dossier, Distrito Federal, México, 2018, pp. 82-89.

Cancino, S., "Permanencias, cambios y tensiones en el proceso de visibilización de la homosexualidad masculina de Xalapa, Veracruz. 1969-2005", tesis para obtener el grado de doctor en Historia y estudios regionales, Universidad Veracruzana, Xalapa, 2012.

Cattan, N. y Leroy, S., “La ville négociée: les homosexual(le)s dan l'espace public parisien”, en Cahiers de geographie du Quebec, 4(151): 9-24, París, 2010.

Cattan, N. y Vanolo, A., "Homosexuality and the city: emotional geographies of clubbing in Paris and Turin", en Paper presented at the International RC21 Session 11 - Does Diversity Divide? Dealing with sexual diversity in 21st century urban settings, Ámsterdan, 2011.

Del Muro, N. et al., "Mercado rosa importancia y valor de mercado", Tesis para obtener el grado de Licenciados en Relaciones Comerciales, Instituto Politécnico Nacional, México, 2012, 110 pp.

Dóniz, J., "Geografía, homosexualidad masculina y cruising en Tenerife, (Canarias, España)”, en Revista Latino-americana de Geografia e Gênero, 6(2): 173-191, Ponta Grossa, Canarias, 2015.

_- "Territorio, género, homosexualidad masculina y sexo: los espacios del cruising en Tenerife", en XXI Coloquio de Historia Canario-Americana, Las Palmas Gran Canaria, 2016, 1-7 pp.

Elder, G., Knopp, L. y Nast, H., "Sexuality and space”, en Gayle, G. y Willmott, C., Geography in America at the dawn of the 21st century, Oxford University Press, Oxford, 2003, 200-208 pp.

Espinosa, I., "El cabaret: espacio de sociabilidad homosexual y sus representaciones en la Ciudad de México, 1946-1955", tesis para obtener en grado de licenciado en Historia, Universidad Nacional Autónoma de México, México, 2017.

Fernández, V., "Comunidad gay y espacio en España”, en Boletín del AGEN, 43: 241-260, España, 2007.

—, "¿Un planeta fuera del armario? La visibilidad gay como objeto de estudio geográfico", en Scripta Nova, 12(43): 1-15, España, 2007b.

Ferreira, E., "Geographies of (in) equalities: space and sexual identities" en Salvador, R., Ponte, F. y Ferreira, E. (ed.), Proceedings of Geographies of Inclusion: challenges and opportunities, e-GEO, Lisboa, 2011, pp. 36-60.

Fimiani, R., "The Role of gay spaces for a gay destination. Gay tourism in Gran Canaria", tesis para obtener el grado de maestro en Geografía humana, Universidad de Dalarna, Högskolan Dalarna, 2014, p. 49.

Fonseca, C. y Quintero, M., "Temas emergentes de los estudios de género", Cámara de Diputados, LX Legislatura y Miguel Ángel Porrúa, México, 2008, 510 pp.

Fuentealba, F., "La visibilidad como opción: manifestaciones espaciales de lo queer en la ciudad de Santiago", en Revista de Geografía Espacios, 6(12): 53-70, Santiago, 2016. 
García, E., “'Del armario al barrio': aproximación a un nuevo espacio urbano”, en Anales de Geografía de la Universidad Complutense, 20: 437-449, Madrid, 2000.

García, M.. "¿Espacios asexuados o masculinidades y feminidades espaciales? Hacia una geografía del género", en SEMANA, 20: 25-51, Barcelona, 2008.

_- "Para no excluir del estudio a la mitad del género humano: un desafío pendiente en la geografía", en Boletín de la Asociación de Geógrafos Españoles, 9: 27-48, Barcelona, 1989.

García, M., "El análisis de género y la geografía: reflexiones en torno a un libro reciente”, en Documents d'Anàlisi Geogràfica, 6: 133-143, Barcelona, 1985.

García, M. y Marín, H., "Creación y apropiación de espacios sociales en el turismo gay: identidad, consumo y mercado en el Caribe Mexicano", en Culturales, 2(1): 71-94, Mexicali, 2012.

Ghinea, G. y Manea, M., "LGBT comunity-constraints and practices of space apropriation in Bucharest", en Analize, Journal of Gender and Feminist Studies, 17(3): 112-136, Bucharest, 2014.

Ghisyawan, K., "Geographies of sexuality. Constructions of space and belonging", en Jorunal of the Departament of Behavioural Sciences, 3(1), Trinidad y Tobago, 2014.

Gómez, M., "Geografía y género: aportes para un debate. El caso del Noa", en La Aljaba, segunda época, 16: 219-222, Luján, 2012.

Guerra, L., "Subjetividades lesbianas en los espacios no inscritos de la identidad", en AISTHESIS, 50: 157-171, Irvine, 2011.

Gutiérrez, L. y Guadarrama, A., "La estatua de sal, de Salvador Novo. Urbanismo e identidad homosexual en la ciudad de México, 1917-1921", en Valenciana, 11(22): 37-52, Morelos, 2018.

Hankok, C. y Chapuis, A., "Geografía de género, geografía feminista en Francia: ¿Una geografía paradójica?”, en Ibarra M. y Escamilla, I. (ed.), Geografías feministas de diversas latitudes, 123-152 pp., Geografía para el siglo XXI, Serie: Textos Universitarios, Instituto de Geografía, unam, México, 2016, 233 pp.

Islas, D., "Zona Rosa como territorio queer. Entre la empresarialidad, el consumo y el crisol de identidades gay", tesis para obtener el grado de licenciado en Geografía humana, Universidad Autónoma Metropolitana, Unidad Iztapalapa, Ciudad de México, 2013, 147 pp.

Karsten, L. y Meertens, D., "La geografía del género: sobre visibilidad, identidad y relaciones de poder", en DOCUMENTS D'ANÀLISI GEOGRÀFICA, 19-20: 181-193, Ámsterdam, 1991.

Kingman, E., "Historia social urbana. Espacios y flujos", Flacso y Ministerio de Cultura, Quito, 2009, 365 pp.

Laguarda, R., "El ambiente: espacios de sociabilidad gay en la ciudad de México, 19681982", en Secuencia, 78: 151-174, Ciudad de México, 2010.

Lan, D., "Los estudios de género en la geografía argentina", en Ibarra M. y Escamilla, I. (eds.), Geografías feministas de diversas latitudes, pp. 55-70, Geografía para el siglo XXI, Serie: Textos Universitarios, Instituto de Geografía, UnAm, México, 2016, 233 pp.

Langarita, J., "Sexo y anonimato. Nota sobre los participantes en encuentros sexuales entre hombres en espacios públicos", en Revista de Dialectología y Tradiciones Populares, 69(2): 349-368, Cataluña, 2014. 
Leroy, S., "Gay Paris: elements for a Geography of homosexuality", en Annales de géographie, 6(646): 579-601, Francia, 2005.

List, M., "Jóvenes corazones gay en la ciudad de México. Género, identidad y sociabilidad en hombres gay" Benemérica Universidad Autónoma de Puebla, Dirección General de Fomento Editorial, Facultad de Filosofía y Letras, Puebla, 2017, 347 pp.

López, A. "Trabajo sexual masculino en contextos turísticos de la Ciudad de México", en López, A. y Van, A. (eds.) Turismo y sexo en México. Cuerpos masculinos en venta y experiencias homoeróticas, Instituto de Geografía, UnAm, México, 2013.

López, A. y Carmona, R., "Turismo sexual masculino-masculino en la Ciudad de México", en Teoría y Praxis 5: 99-112, Ciudad de México, 2008.

López, A. y Sánchez, A., "Dinámica territorial del deseo queer en Monterrey”, en Ciudades, 62: 25-33, Puebla, 2004.

López, A. y Van, A., “Turismo y sexo en México”. Cuerpos masculinos en venta y experiencias homoeróticas", UnAM, Instituto de Geografía, México, 2013.

Lozano, I., "Prácticas políticas identitarias de hombres gay de la ciudad de México: entre la tensión y la heternormalización", en Revista Interdisciplinaria de Estudios de Género, 2(4): 126-153, Ciudad de México, 2016.

Luna, E., "Geografía de la diversidad: Chapinero (UPZ99) como distrito LGBT de Bogotá", en Revista Geográfica de América Central, 2: 1-16, Heredia, 2011.

Maliepaard, E., "Bisexuals in space and geography: more-than-queer?", en Fennia, 1: 148159, Nijmegen, 2015.

Marín, H., "Creación y apropiación de espacios sociales dentro del turismo gay: identidad, consumo y mercado en Cancún Quintana, Roo", tesis para obtener el grado de maestro en Antropología aplicada a Estudios Regionales, Universidad de Quintana Roo, Chetumal, 2012, 131 pp.

Massey, D., "Space, place and gender", University of Minessota Press, Minneapolis, 1994, $289 \mathrm{pp}$.

McDowell, L., "Género, identidad y lugar. Un estudio de las geografías feministas", ediciones Cátedra, Madrid, 2000, 390 pp.

Mendoza, C., "Entre el negocio y el placer. Turismo sexual masculino en Puerto Vallarta", en Estudios y Perspectivas en Turismo, 24(4): 889-907, Puerto Vallarta, 2015.

Moner, C., Royo, M. y Ruiz, M., "Oferta y demanda en el mercado turístico homosexual: una propuesta de estrategias de intercambio para la mejora del marketing en el segmento", en Cuadernos de Turismo, 29: 171-197, Murcia, 2008.

Montero, J., "Feminismo: un movimiento crítico", en Intervención Psicosocial Dossier, 15(2): 167-180, Madrid, 2006.

Monterrubio, C., "Comunidades receptoras y percepciones: un estudio sobre turismo y sexualidad" en Teoría y Praxis, 5: 145-160, Estado de México, 2008.

Moral, J., "Homosexualidad en la juventud mexicana y su distribución geográfica", en Papeles de Población, 67: 112-134, CIEAP/UAEM, México, 2011.

Olarte, C., "Masculinidad y afectividad en el espacio público: la percepción de los varones ante las prescripciones sociales de género. Análisis en un Universidad de Tabasco", tesis para obtener en grado de doctor en Psicología, Universidad Veracruzana, Xalapa, 2017.

O' Riordan, K., "Bisexual spaces: a geography of sexuality and gender" en Feminist Review, 81: 127-137, Estados Unidos, 2005. 
Pacheco, X., "El espacio del género en Geografía”, en Revista Geográfica de América Central, 34: 103-112, Costa Rica, 1997.

Páramo, P. y Burbano, A., "Género y espacialidad”, en Universitas Psychologica, 10(1): 6170, Pontificia Universidad Javeriana, Bogotá, 2011.

Poveda. E. y Ávila, J., "Bases conceptuales para determinar los hábitos de consumo del segmento LGBT en la ciudad de Bogotá D.C.", tesis para obtener el grado de licenciados en Administración de Empresas, Universidad Javeriana, Bogotá, 2008, $97 \mathrm{pp}$.

Quinceno, N. y Sanín, P., "Estigmas territoriales y distinciones sociales: configuraciones espaciales en la ciudad de Medellín”, en Anagramas, 7(14): 115-132, Universidad de Medellín, Medellín, 2009.

Quintero, M. y Fonseca, C., "Importancia de la vinculación de la categoría de género y la ciudad", en Fonseca, C. y Quintero, M. (Ed.) Temas emergentes de los estudios de género, pp. 31-52, Cámara de Diputados, LX Legislatura y Miguel Ángel Porrúa, México, 2008, 510 pp.

Ramírez, F., "Cuestionamientos a la Geografía a partir del cruising entre hombres en Bogotá", en Revista Latino-americana de Geografia e Gênero, 4(2): 134-147, Ponta Grossa, Bogotá, 2013.

Regalado, O. et al., "Bases para la segmentación del mercado homosexual en la ciudad de Lima: un enfoque para el sector de entretenimiento" en TEC Empresarial, 11(3): 716, Lima, 2017.

Reyes, M., "Plan marketing para el desarrollo de una app de viajes dirigida al pink market", tesis para obtener la especialidad en Marketing Estratégico de Negocios, Instituto Politécnico Nacional, Ciudad de México, 2017, 125 pp.

Robles, A., "Ensayo para una cartografía maricona de Bogotá: el centro", en Maguaré, 29(2). 287-314, Bogotá, 2015.

Román, M. y Velázquez, I., "Guía de urbanismo con perspectiva de género", Consejería de Política Social, Mujer e Inmigración, Comunidad Autónoma de la Región de Murcia e Instituto de la Mujer de la Región de Murcia, Murcia, 2008, 68 pp.

Ruiz, P. "Urbanism and gay identity”, en New Visions For Public Affairs, 4, 1-15, Spring, San Francisco, 2012.

Saborio, M., "Ciudad y relaciones de género", en Octava Conferencia Regional sobre la Mujer de América Latina y el Caribe, CEPAL, El Salvador, 1999, 1-31 pp.

San Martín, I., "Visibilidad de la comunidad gay y lésbica en el espacio público de la ciudad de México: la Zona Rosa", en Revista Digital Universitaria, 11(9): 1-14, DGSCA-UNAM, Ciudad de México, 2010.

Sánchez A. y López A. "Visión geográfica de los lugares gay de la Ciudad de México", en Cuicuilco, Vol. 7 (18), 1-17, Ciudad de México, 2000.

Sánchez, J., "Urbanismo y geografía urbana: dos ciencias distintas pero complementarias”, en Lurralde, 15: 225-234, BIBLID, Salamanca, 1992.

Sánchez, R., "Lugares gays en la ciudad de México y su relación con la construcción de identidades", tesis para obtener el grado de maestro en Geografía, Universidad Nacional Autónoma de México, 2004, 185 pp.

Santos, X., "Espacios disidentes en los procesos de ordenación territorial”, en Pegada, 4(2): 87-120, Santiago de Compostela, 2003. 
Seva, C., "Investigación de procesos de cambio social: evolución reciente de la percepción de la homosexualidad en la comunidad de valencia", en Sociología, Universidad de Alicante, Valencia, 2011, 3-52 pp.

Simonetto, P., "Fronteras del deseo. Homosexualidad, sociabilidad y afecto en la ciudad de Buenos Aires (1950- 1983)", en Artigo, Cadernos Pagu, 49: 2-31, Buenos Aires, 2017.

Soto, P., "Hacia la construcción de unas geografías de género en la ciudad. Formas de habitar y significar los espacios urbanos en Latinoamérica”, en Perspectiva Geográfica, 23(2): 1-24, Ciudad de México, 2018.

Tamayo J. y Sophie, I., "El turismo rosa en Playa del Carmen, Quintana Roo, México", Trabajo presentado en el Congreso de Investigación Turística Aplicada, Toluca, 2015, 1-10 pp.

Trachana, A., “Espacio y género”, en Ángulo Recto, 5(5): 117-131, Madrid, 2013.

Townsend, J., "Feminismo, geógrafos y geógrafas feministas y el resurgimiento de la geografía crítica”, en Doc. Anál. Geogr., 40: 175-187, Durham, 2002.

Vargas, G., "Espacio y territorio en el análisis geográfico", en Reflexiones, 91(1): 313-326, San José, 2012.

Vargas, S. y Alcalá, B., "Aspectos territoriales de la prostitución masculina vinculada al turismo sexual en Acapulco", en Estudios y Perspectivas en Turismo, 24(4): 867-888, Acapulco, 2015.

Vargas, S. y Alcalá, B., "Espacios homoeróticos y turismo sexual en Acapulco", en Territorios, 1-8, Acapulco, 2015.

Vartabedian, J., "Geografía travesti: cuerpos, sexualidad y migraciones de travestis brasileñas (Rio de Janeiro-Barcelona)", tesis para obtener el grado de doctora en Antropología social y cultural, Universitat de Barcelona, Barcelona, 2012, 396 pp.

Vasconcelos, R., "Geografia da diversidade: Breve análise das territorialidades homossexuais no Rio de Janeiro", en Revista Latino-americana de Geografía e Gênero, 1(1): 14-20, Ponta Grossa, Río de Janeiro, 2010.

Velázquez I., "Historia del uso del espacio público. Género y urbanismo en la actualidad", en Apodaka, M. (ed.), Urbanismo inclusivo las calles tienen género, 21-29, Eusko Jaurlaritzaren Argitalpen Zerbitzu Nagusia, Servicio Central de Publicaciones del Gobierno Vasco, Vitoria Gasteiz, 2012.

Veleda, S., "Geografías femeninas brasileñas. Un punto de vista", en Ibarra M. y Escamilla, I. (eds.), Geografías feministas de diversas latitudes, pp. 71-94, Geografía para el siglo XXI, Serie: Textos Universitarios, Instituto de Geografía, unam, México, 2016, $233 \mathrm{pp}$.

Veleda, S. y Lan, D., "Estudios de geografía del género en América Latina: un estado de la cuestión a partir de los casos de Brasil y Argentina”, en Doc. Anàl. Geogr., 49: 99-108, Rio Grande y Provincia de Buenos Aires, 2007.

Wolfok, L. Nuñez, G. y Ponce, P., "Sexualidad, desarrollo, políticas públcas y turismo LGBTTTI en México" en Revista turismo y desarrollo local, 9(21): 1-15, Sonora, 2016.

Zarur, A., "El fenómeno gay contemporáneo, de lo moralmente inaceptable, a segmento de mercado", en Gestión y Estrategia, 40: 51-63, México, 2011. 